\section{Dr. Murray, et al reply}

\section{To the Editor:}

We thank Drs. Hettema and Smit for their letter ${ }^{1}$ and their interest in our report ${ }^{2}$. We agree that a discrepancy between our finding of an increase in skin fluorescence in patients with systemic sclerosis (SSc) and their finding of no increased fluorescence may be due to either different measurement systems or different locations of measurement. The technique that we used to take these measurements works in a way similar to the advanced glycation endproducts (AGE) reader and therefore we would not expect different results on the basis of the equipment (however, we accept that both systems would need to be tested side by side to be confident of this). We studied dorsal aspects of the hand and forearm (as opposed to the ventral site used in the study by Hettema, et $a l^{3}$ ) and agree that difference in sites studied could influence results.

Regarding the use of the AGE reader at 1 site as opposed to our method of taking several readings over the upper limbs, we felt that in SSc, where fibrosis occurs to varying extents at different sites depending upon the disease severity and subtype, we were justified in assessing several different locations including both clinically affected and unaffected skin.

We accept that there is a variation in fluorescence over different body sites, as shown by $\mathrm{Na}$, et $a l^{4}$ : the differences observed between sites occur in both the control and patient cohorts.

A key point in our study is that the difference that we identified in skin fluorescence was found only in patients with diffuse cutaneous SSc. Hettema, et al included in their study only patients with limited cutaneous $\mathrm{SSc}$, and so our results are not inconsistent, although we did find a trend for increased fluorescence in patients with limited cutaneous SSc. We do, however, aim to carry out validation of the technique against biopsies as part of our ongoing research program.
ANDREA K. MURRAY, PhD, Institute of Inflammation and Repair, Centre for Musculoskeletal Research, University of Manchester, Manchester Academic Health Science Centre, Manchester; CHRISTOPHER E.M. GRIFFITHS, FRCPath, MD, FMedSci, Dermatology Centre, University of Manchester, Manchester Academic Health Science Centre, Salford Royal National Health Service Foundation Trust, Salford; ARIANE HERRICK, FRCP, Institute of Inflammation and Repair, Centre for Musculoskeletal Research, University of Manchester, Manchester Academic Health Science Centre, Manchester, UK. Address correspondence to Dr. A.K. Murray, University of Manchester, Translational Medicine, Oxford Road, Manchester M13 9PL, UK.

E-mail: Andrea.Murray@manchester.ac.uk

\section{REFERENCES}

1. Hettema M, Smit AJ. Local differences in skin autofluorescence may not reflect similar differences in oxidative stress exposure [letter]. J Rheumatol 2013;40:206.

2. Murray AK, Moore TL, Manning JB, Griffiths CE, Herrick AL. Noninvasive measurement of skin autofluorescence is increased in patients with systemic sclerosis: An indicator of increased advanced glycation endproducts? J Rheumatol 2012;39:1654-8.

3. Hettema ME, Bootsma H, Graaff R, de Vries R, Kallenberg CG, Smit AJ. Skin autofluorescence, as marker of accumulation of advanced glycation endproducts and of cumulative metabolic stress, is not increased in patients with systemic sclerosis. Int J Rheumatol 2011;2011:417813.

4. Na R, Stender IM, Ma L, Wulf HC. Autofluorescence spectrum of skin: Component bands and body site variations. Skin Res Technol 2000;6:112-7.

J Rheumatol 2013;40:2; doi:10.3899/jrheum.121275 